\title{
Current Perspective of Symbiotic Organisms Search Technique in Cloud Computing Environment: A Review
}

\author{
Ajoze Abdulraheem Zubair ${ }^{1}$ \\ Shukor Bin Abd Razak², Md. Asri Bin Ngadi ${ }^{3}$ \\ School of Computing, Faculty of Engineering \\ Universiti Teknologi Malaysia,81310 Skudai \\ Johor Bahru, Johor Malaysia
}

\author{
Aliyu Ahmed ${ }^{4}$ \\ Department of Mathematics \\ Bauchi State University Gadau \\ 751105 Itas-Gadau Bauchi, Nigeria
}

\begin{abstract}
Nature-inspired algorithms in computer science and engineering are algorithms that take their inspiration from living things and imitate their actions in order to construct functional models. The SOS algorithm (symbiotic organisms search) is a new promising metaheuristic algorithm. It is based on the symbiotic relationship that exists between different species in an ecosystem. Organisms develop symbiotic bonds like mutualism, commensalism, and parasitism to survive in their environment. Standard SOS has since been modified several times, either by hybridization or as better versions of the original algorithm. Most of these modifications came from engineering construction works and other discipline like medicine and finance. However, little improvement on the standard SOS has been noticed on its application in cloud computing environment, especially cloud task scheduling. As a result, this paper provides an overview of SOS applications in task scheduling problem and suggest a new enhanced method for better performance of the technique in terms of fast convergence speed.
\end{abstract}

Keywords-Cloud computing; cloud resource management; cloud task scheduling; symbiotic organisms search; entrapment; convergence speed

\section{INTRODUCTION}

The term "cloud computing" refers to a fully centralized, scalable, on-demand computing network with distributed virtual infrastructure, storage, and pay-per-use services[1][2][3]. Resource management in infrastructure as a service (IaaS) is one of the most important challenges of cloud computing especially cloud task scheduling. Task Scheduling is an optimization problem that falls into the NP-hard class[4][5][6]. Therefore, using conventional search algorithms to find an optimal mapping between tasks and resources in a short period of time becomes almost impossible.

Many metaheuristic algorithms have been proposed to solve optimization problems in recent decades. Metaheuristic research around the world has resulted in optimization techniques that have proved to be superior to conventional gradient-based approaches[7][8][9][10]. Almost all metaheuristic algorithms have the following features in common: nature-inspired, probability distributions, do not need significant gradient information, and many parameters that must be tailored to the problem at hand. Several metaheuristic algorithms that mimic the actions of insect or animal classes in nature have been developed using a combination of deterministic rules and randomness[9][11]. Many of the optimization problems that can be formulated are extremely nonlinear, with multimodal objective landscapes and a series of dynamic, nonlinear constraints[12][13][14].

Optimization algorithms are intelligent self-learning algorithms derived from the observation and mimicking of intelligent processes and actions observed in nature, usually based on swarm intelligence[9][15]. The optimization problems that have piqued interest in metaheuristic approaches range widely in complexity, from single to multi-objective, continuous to discrete, constrained to unconstrained and largescale global optimization problems. Therefore, solving these problems is not always easy due to their complicated behaviour[1][9][16][17][18]. Studies of swarm behavior can perhaps be regarded as a field of artificial intelligence (AI), is saddled with the responsibilities of collecting information about the behaviour of organisms in self organized environment. Symbiotic Organisms Search algorithm (SOS) is an $\mathrm{SI}($ Swarm Intelligence)-based recently developed metaheuristic algorithm that was inspired by nature[19]. The SOS algorithm mimics the collaborative behavior observed in nature among individuals. Symbiotic relationships between paired organisms in an ecosystem define cohabitation behavior of different species which include mutualism, commensalism, and parasitism. Symbiosis is a close relationship between organisms that last over a period[20][21][22][23]. Overview of the relationship among distinct species is depicted in Fig. 1.

Mutualism is the interaction between two species with mutual benefit, which means that both benefit from the relationship. Commensalism happens when one species forms a bond with a different species, with one species gaining while the other is unaffected. When two species form a relationship in which one benefits and the other hurts, it is referred to as parasitism. Both mutualism and commensalism operations focus on creating new species for the next generation by allowing the search procedure to find solutions to the problems within the solution search space, thereby improving the algorithm's exploratory capability. The parasitism phase, on the other hand, focuses on increasing exploitative capability by allowing the search process to escape entrapment at local optimality. 




Fig. 1. Vector Illustration of Symbiosis.

The optimization analysis group and other similar domains have been paying considerable interest to the algorithm because of its deployment simplicity and consistency.

Furthermore, in comparison to other alternative algorithms or competitors such as GA, ACO, PSO, and DE, the SOS algorithm has drastically risen in its area of application to several optimization realms but little in cloud computing environments. Therefore, this paper provides a comprehensive analysis of the standard SOS algorithm, its basic concepts and structures, variants, and hybrid implementations for addressing constrained, unconstrained, single objective, multiple objectives, large scale global optimization problems, and practical oriented real world optimization problems in a cloud computing setting. This paper's major contributions are as follows:

- A comprehensive review of the traditional SOS algorithm.

- A look at SOS varieties and hybridization strategies.

- Identification and presentation of the different applications of the SOS algorithm in task scheduling problems within cloud computing context.

The rest of the paper is structured as follows: Section 2 introduces the fundamental concept and summarized work on standard SOS algorithm; Section 3 presents a review of research works on SOS algorithms, including variants and hybrid versions of the regular algorithm, while Section 4 concludes the study and provides viable future directions.

\section{Symbiotic ORganisms SEARCH AlgORITHM (SOS)}

Cheng and Prayogo [19] developed a framework for simulating the symbiotic relationship between species in an environment, using it to solve mathematical and engineering design problems. Three distinct search processes govern the next possible solution, which are modeled after three basic symbiotic interactions: mutualism, commensalism, and parasitism.

\section{A. Mutualism Phase}

This is the first stage which entails selecting organisms based on their fitted values. In this phase, two organisms $Z^{i}$ and $Z^{j}$ (where $\mathrm{i} \neq \mathrm{j}$ ) are selected to interact with each other. The two distinct organisms benefit from one another. The mathematical formulations of these procedures are presented as in (1) and (2).

$Z^{i \_n e w}=Z^{i}+\gamma(0,1) \times\left[Z^{\text {best }}-M_{v} \times B^{f-1}\right]$
$Z^{j \_n e w}=Z^{j}+\gamma(0,1) \times\left[Z^{\text {best }}-M_{v} \times B^{f-2}\right]$

The joint relation vector between $Z^{i}$ and $Z^{j}$ denoted by $M_{v}$ and benefit factor $\left(B^{f}\right)$ are evaluated using the mathematical formulars in equations (3), (4), and (5) respectively.

$M_{v}=\frac{Z^{i}+Z^{j}}{2}$

$B^{f-1}=1+\operatorname{round}(\gamma(0,1))$

$B^{f-2}=1+\operatorname{round}(\gamma(0,1))$

The new species $Z^{i \_n e w}$ and $Z^{j \_n e w}$ are created by sculpting their structure from $M_{v}$ and $B^{f}$ matching to the existing population's fittest species $\left(Z^{\text {best }}\right)$. However, while $M_{v}$ specifies the mutual bond between different species, $B^{f}$ denotes the degree of value gained by each species as a result of their interaction. $\boldsymbol{\gamma}(0,1)$ denotes a vector of uniformly distributed random numbers ranging from 0 to 1 . The fitness values of these new species $Z^{i_{-} \text {new }}$ and $Z^{j_{-} \text {new }}$ are each evaluated and compared with their respective predecessor to select the next generation of the ecosystem. If the fitness values of the new species are better than their predecessor, then they automatically move to the next generation otherwise they are rejected, and the old species remain. Note that worst fitness values are rejected and replaced.

\section{B. Commensalism Phase}

In this phase, only one organism $Z^{i}$ can increase his or her fitness value. This is achieved by randomly select organism $Z^{j}$ which is neutrally affected in their relationship. The commensalism relationship between these two organisms is established using the mathematical equation as in (6).

$Z^{i \_n e w}=Z^{i}+\gamma(-1,1) \times\left(Z^{\text {best }}-Z^{j}\right)$

So, the beneficial contribution of organism $Z^{j}$ to organism $Z^{i}$ is computed using $\left(Z^{\text {best }}-Z^{j}\right)$ as in (6). Similar to the mutualism process, the newly created organism $\left(\left(Z_{-}^{i}\right.\right.$ new $)$ can only substitute its predecessor $\left(Z^{i}\right)$ if and only if its fitness value is higher; otherwise, $\left(Z^{i}\right)$ is retained. 
Algorithm 1 below outlines the processes of the standard symbiotic organism search (SOS) algorithm.

Algorithm 1: Pseudo-code of Symbiotic Organism Search algorithm

Define input variables, objective function, and problem dimension.

// Population size (ecosize), maximum iterations (Maxitern)

Initialize population with respect to population size(ecosize)

Identify the best organism in the ecosize ( $\mathrm{Z}^{\text {best }}$ )

\section{Start SOS Looping:}

While itern<maxitern

For $\mathrm{i}=1$ : ecosize
Mutualism Phase

Select species $Z^{i}$ and $Z^{j} \quad(i \neq \mathrm{j})$ Benefit

compute the common vector $\left(M_{v}\right)$ as in (3) and the

$$
\text { factor }\left(B^{f-1} \text { and } B^{f-2}\right) \text { as in (4) and (5) }
$$

Using (1) and (2) to create the new species

$$
Z^{i \_n e w} \& Z^{j \_n e w} \text { and assess their strengths. }
$$

If the strengths of the new species are better, then

replace the predecessors

\section{Commensalism phase}

Select species $Z^{j}$ randomly $(i \neq j)$

Using (6) to create new species $Z^{i \_n e w}$ and

assess

its strength

better, then

If the strength of the new species is

replace the predecessor.

\section{Parasitism Phase}

Select species $Z^{j}$ randomly $(i \neq j)$

Produce parasite vector $Z^{p}$ by amending $Z^{i}$, assess the strength

If the strength of the parasite vector $\left(Z^{p}\right)$ is better, then replace $Z^{j}$ with $Z^{p}$

\section{End for}

Update best species $Z^{\text {best }}$ of the existing population

\section{End while}

\section{Parasitism phase}

The phenomenon of parasitism can be best described by the interaction between a mosquito and human. Once the human is bitten by mosquito, the process create parasite in the human body. The parasite present in the human body reproduces itself and overwhelms the human host through disease infection which may lead to death. On the contrary, if the human body has better immunity, then it protects itself and the parasite gets eliminated from the body.

The human host is harmed in this type of interaction, while the anopheles mosquito, which is the parasite carrier, remains unharmed, the plasmodium parasite thrives and replicates within the body system. The parasitism interaction between two organisms $Z^{i}$ and $Z^{j}$ with $(\mathrm{i} \neq \mathrm{j})$ is introduced in the SOS model as follows:

If $Z^{i}$ is assigned to the anopheles' mosquito which is selected randomly from the search space, fine-turned its dimension to create an artificial vector or (parasite vector) denoted by $Z^{p}$. Similarly, the organism $Z^{j}$ is equally selected randomly from the search space and serves as host to $Z^{p}$. The parasite vector, $Z^{p}$, tries to replace the host $Z^{j}$ in the ecosystem. If $Z^{p}$ has a higher fitness value than $Z^{j}, Z^{p}$ replaces $Z^{j}$ otherwise, $Z^{j}$ gains immunity, fights back, and eliminate $Z^{p}$ from the ecosystem.

The mathematical formulation of selection of species guided by their strength is as in (7) and (8): -

Randomly select $Z^{j}$ with $\mathrm{i} \neq \mathrm{j}$

Create a parasite vector $Z^{p}$ from $Z^{i}$ using a random number.

If $f\left(Z^{p}\right)>f\left(Z^{j}\right)$ then

$Z^{j} \leftarrow Z^{p}$

else

$Z^{j \_n e w}=Z^{j}$

\section{The Most ReCEnt SOS VERSIONS FOR TASK SCHEDULING PROBLEMS}

So far, different implementations of SOS have been introduced due to various type of task scheduling optimization problems. Therefore, it is critically important to examine the enhanced and improved variants of the SOS algorithm as they contribute to task scheduling issues in the cloud. Fig. 2 shows the classification of variant symbiotic organisms search algorithm. Some of the modified SOS algorithms considered in this review are highlighted in Table 1.

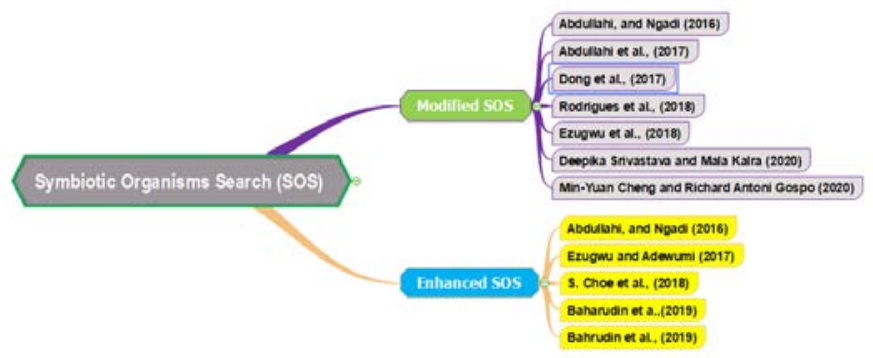

Fig. 2. Taxonomy of Variant Symbiotic Organisms Search Algorithm. 
TABLE I. THE SUMMARY OF LITERATURES ON MODIFIED SyMBIOTIC ORGANISM SEARCH (SOS) ALGORITHMS

\begin{tabular}{|c|c|c|c|c|c|c|c|c|}
\hline $\mathrm{S} / \mathrm{N}$ & Authors & Title & Objectives & $\begin{array}{l}\text { Modified } \\
\text { technique }\end{array}$ & $\begin{array}{l}\text { Benchmarked } \\
\text { Technique }\end{array}$ & $\begin{array}{l}\text { Journal/ } \\
\text { Conference }\end{array}$ & Publishers & Remarks \\
\hline 1 & $\begin{array}{l}\text { Abdullahi, } \\
\text { and Ngadi } \\
\text { (2016) }\end{array}$ & $\begin{array}{l}\text { Symbiotic } \\
\text { Organism Search } \\
\text { optimization- } \\
\text { based task } \\
\text { scheduling in } \\
\text { cloud computing } \\
\text { environment }\end{array}$ & $\begin{array}{l}\text { Minimizing } \\
\text { makespan }\end{array}$ & DSOS & PSO & $\begin{array}{l}\text { Future } \\
\text { Generation } \\
\text { Computer } \\
\text { Systems }\end{array}$ & Elsevier & $\begin{array}{l}\text { T-test analysis of the } \\
\text { proposed method revealed } \\
\text { that DSOS performs } \\
\text { significantly better than } \\
\text { PSO, especially for large } \\
\text { search spaces. }\end{array}$ \\
\hline 2 & $\begin{array}{l}\text { Abdullahi } \\
\text { et al., } \\
\text { (2017) }\end{array}$ & $\begin{array}{l}\text { "Chaotic } \\
\text { symbiotic } \\
\text { organisms search } \\
\text { for task } \\
\text { scheduling } \\
\text { optimization on } \\
\text { cloud computing } \\
\text { environment" }\end{array}$ & $\begin{array}{l}\text { Minimizes } \\
\text { cost and } \\
\text { makespan }\end{array}$ & CSOS & SOS, PSO & $\begin{array}{l}\text { 6th ICT } \\
\text { International } \\
\text { Student Project } \\
\text { Conference }\end{array}$ & $\begin{array}{l}\text { UTM/RUG/15H99 } \\
\text { RMC Universiti } \\
\text { Teknologi } \\
\text { Malaysia. }\end{array}$ & $\begin{array}{l}\text { The key idea is to } \\
\text { incorporate a chaotic map, } \\
\text { which enlarges the search } \\
\text { space and provides diversity, } \\
\text { to avoid premature } \\
\text { convergence of SOS at early } \\
\text { stages of the optimization } \\
\text { process. }\end{array}$ \\
\hline 3 & $\begin{array}{l}\text { Dong et } \\
\text { al., (2017) }\end{array}$ & $\begin{array}{l}\text { CTS-SOS: Cloud } \\
\text { task scheduling } \\
\text { based on the } \\
\text { symbiotic } \\
\text { organisms search }\end{array}$ & $\begin{array}{l}\text { Minimizing } \\
\text { makespan }\end{array}$ & CTS-SOS & RR and ACO & $\begin{array}{l}\text { Communications } \\
\text { in Computer and } \\
\text { Information } \\
\text { Science }\end{array}$ & Springer & $\begin{array}{l}\text { The results of the } \\
\text { experiments demonstrate } \\
\text { that CTS-SOS can have } \\
\text { improved resource } \\
\text { optimization and scheduling, } \\
\text { efficiently minimize the } \\
\text { makespan, and increase the } \\
\text { performance of processing } \\
\text { tasks and user satisfaction. }\end{array}$ \\
\hline 4 & $\begin{array}{l}\text { Rodrigues } \\
\text { et al., } \\
\text { (2018) }\end{array}$ & $\begin{array}{l}\text { A Search } \\
\text { Algorithm for } \\
\text { Flow Shop } \\
\text { Scheduling } \\
\text { Issues based on } \\
\text { Modified } \\
\text { Symbiotic } \\
\text { Organisms } \\
\text { Search } \\
\text { Technique }\end{array}$ & $\begin{array}{l}\text { Minimizing } \\
\text { makespan }\end{array}$ & ISOS & SOS & $\begin{array}{l}\text { IEEE Congress } \\
\text { on Evolutionary } \\
\text { Computation } \\
\text { (CEC) }\end{array}$ & IEEE & $\begin{array}{l}\text { The proposed modification } \\
\text { improved the performance of } \\
\text { the SOS algorithm in the } \\
\text { search for the global } \\
\text { optimum value in most of } \\
\text { the instances. }\end{array}$ \\
\hline 5 & $\begin{array}{l}\text { Ezugwu et } \\
\text { al., (2018) }\end{array}$ & $\begin{array}{l}\text { Symbiotic } \\
\text { organisms search } \\
\text { algorithm for the } \\
\text { unrelated parallel } \\
\text { machines } \\
\text { scheduling with } \\
\text { sequence- } \\
\text { dependent setup } \\
\text { times }\end{array}$ & $\begin{array}{l}\text { Makespan } \\
\text { minimization }\end{array}$ & SOS-LPT & $\begin{array}{l}\text { ACO, ACOII, } \\
\text { GADP, } \\
\text { SADP, SOS }\end{array}$ & PLoS ONE & PLOS & $\begin{array}{l}\text { The incorporation of the } \\
\text { local search improvement } \\
\text { mechanism into the SOS } \\
\text { scheme has been shown to } \\
\text { introduce diversity in the } \\
\text { search process and avoid } \\
\text { premature convergence. }\end{array}$ \\
\hline 6 & $\begin{array}{l}\text { Deepika } \\
\text { Srivastava } \\
\text { and Mala } \\
\text { Kalra } \\
(2020)\end{array}$ & $\begin{array}{l}\text { Improved } \\
\text { symbiotic } \\
\text { organism search } \\
\text { based approach } \\
\text { for scheduling } \\
\text { jobs in cloud }\end{array}$ & $\begin{array}{l}\text { Makespan } \\
\text { minimization }\end{array}$ & ISOS & PSO & $\begin{array}{l}\text { (ICIIL 2019) } \\
\text { International } \\
\text { conference on } \\
\text { IoT Inclusive } \\
\text { Life }\end{array}$ & Springer & $\begin{array}{l}\text { The results of the } \\
\text { experiments show a better } \\
\text { performance of the improved } \\
\text { technique over the } \\
\text { benchmarked PSO algorithm }\end{array}$ \\
\hline 7 & $\begin{array}{l}\text { Min-Yuan } \\
\text { Cheng- } \\
\text { and } \\
\text { Richard } \\
\text { Antoni } \\
\text { Gosno } \\
(2020)\end{array}$ & $\begin{array}{l}\text { SOS } 2.0: \text { an } \\
\text { evolutionary } \\
\text { approach for } \\
\text { SOS algorithm }\end{array}$ & $\begin{array}{l}\text { Minimization } \\
\text { of task } \\
\text { execution } \\
\text { time }\end{array}$ & SOS 2.0 & SOS & $\begin{array}{l}\text { Evolutionary } \\
\text { Intelligence }\end{array}$ & Springer & $\begin{array}{l}\text { The integration of SPU and } \\
\text { SOS } 2.0 \text { 's chaotic sequence } \\
\text { provide a significantly } \\
\text { improved balance within the } \\
\text { algorithm's searching pattern } \\
\text { exploration and exploitation. }\end{array}$ \\
\hline
\end{tabular}




\section{A. Modified SOS}

Modified symbiotic organism search technique is one in which either one or two of the operators are improved to enhance the efficiency of the algorithm in order to optimize fast convergence time while avoiding entrapment at the local optimal region[15][21]. In most cases, either the mutualism or commensalism phases, or both, are strengthened by adding a random weighted reflective parameter or converting continuous outcomes to discrete results among approaches.

A symbiotic organism search optimization-based task scheduling technique has been proposed in the work of [24] to schedule a collection of independent tasks in a cloud computing environment. The proposed technique used various types of distributions to gain insight into the proposed method's performance trend. In addition, to account for the finite nature of cloud resources, a discrete version of SOS was introduced. To assess the suitability of the proposed approach, four types of data set were used in the experimental setup: regular, leftskewed, right-skewed, and uniform distributions Furthermore, the performance of DSOS over SAPSO improves with increasing search space. According to[25], an investigation to a scheduling issue using a unique chaotic SOS algorithm to save time and expenses has been presented. The key idea is to perform a chaotic map, which expands the search area and generates diversity, to prevent the SOS algorithm from prematurely converging in the early stages of the optimization process.

In the work of [26], an optimized SOS algorithm for use in workflow-scheduling problems has been suggested. The proposed algorithm selects three steps of the SOS algorithm without regard to the population's pre-defined symbiotic relationship. Following the selection of solutions, a special method is selected to assign each solution to a symbiotic relationship. The proposed algorithm's performance was tested using twenty standard samples of the workflow-scheduling problem, and it was found to be more effective than the standard SOS. In another study, Improved Symbiotic Organism Search-Based Approach for Cloud Job Scheduling has been presented by [27]. The technique presents a discrete algorithm based on Improved Symbiotic Organism Search (ISOS) for scheduling independent tasks with the sole aim of mapping of various tasks to the best available cloud resources so as to minimize makespan and computational cost. Experimental results show a better performance of the improved technique over the benchmarked PSO algorithm.

According to [28] a reconstructed mathematical model for cloud task scheduling with additional approximate end time to the proposed design has been presented. By implementing a cloud task scheduling protocol based on the SOS (CTS-SOS) process, a continuous search space is obtained. The CTS-SOS algorithm more accurately optimizes and schedules time, and it effectively reduced the makespan, improved the efficiency of processing operations, and increased customer loyalty. Furthermore, the results of the simulation using CloudSim toolkit shows that the CTS-SOS algorithm outperform Round
Robin and ACO algorithms. Another similar work proposed an SOS algorithm for scheduling unrelated parallel machines with sequence-dependent startup times [29]. The technique developed a new solution of representative and decoding procedure to enhance the capacity of SOS algorithm for heterogenous parallel machine scheduling problems. The problem of minimizing makespan in the scheduling of unrelated parallel machines with sequence-dependent initialization times has been solved using the proposed technique.

SOS 2.0: An Evolving Solution to the SOS Algorithm has been presented by [30]. The proposed technique integrates selfparameter updating (SPU) method into the search process to enhance its exploration capability. Furthermore, a chaotic map for generating chaotic behaviour was adopted to enhance its exploitation process thereby providing faster convergence. The combination of SPU and chaotic sequence provide adequate balance between local and global search process as well as avoiding premature convergence. The experimental result shows that SOS 2.0 performed better than the basic SOS and other several improved techniques.

\section{B. Hybrid Symbiotic Organisms Search Algorithm}

The modified/improved versions of SOS are faced with some challenges related to solving some complex optimization problems that needs extra synergy to resolve. Since there is no single technique that can address all optimization problems, the hybridized algorithms are more likely to be better in dealing with complex optimization issues and as such can produce a better result. The main aim of hybridizing two or more optimization techniques is to harness the complementary benefits of the techniques involved to produce a better solution[29][31][32]. Current literatures on the usage of SOS to address a variety of complex optimization and real-life problems have shown that the implementation of the SOS algorithm needs additional effort to produce high-quality performance. Table 2 highlight the summary of the literatures on hybridized SOS algorithm, while Table 3 presents analysis of some of the performance metrics used to measure the algorithms performance.

An optimization algorithm for task scheduling in cloud computing environment using hybrid symbiotic organisms search technique has been presented in [31]. The proposed technique integrated the Simulated Annealing (SA) method with the basic SOS. The SOS employs fewer control parameters and is highly flexible, has excellent exploration and convergence capabilities. The proposed technique employs SA's systematic reasoning ability to find better solutions on the local region identified by SOS, thereby enhancing SASOS's exploitative ability. Furthermore, a fitness function was introduced to increase the degree of resource utilization thereby minimizing makespan while optimizing the degree of imbalance among the virtual resources. The result of the experiment indicates a better performance of the hybridized technique (SASOS) over the basic SOS algorithm. 
TABLE II. THE FOLLOWING IS A SUMMARY OF THE LITERATURES ON HYBRID SYMBIOTIC ORGANISM SEARCH (SOS) ALGORITHMS

\begin{tabular}{|c|c|c|c|c|c|c|c|c|}
\hline $\mathbf{S} / \mathbf{N}$ & Authors & Title & Objectives & $\begin{array}{l}\text { Hybridized } \\
\text { Technique }\end{array}$ & $\begin{array}{l}\text { Benchmarked } \\
\text { Technique }\end{array}$ & $\begin{array}{l}\text { Journal/ } \\
\text { Conference }\end{array}$ & Publishers & Remarks \\
\hline 1 & $\begin{array}{l}\text { Abdullahi, } \\
\text { and Ngadi } \\
(2016)\end{array}$ & $\begin{array}{l}\text { Hybrid Symbiotic } \\
\text { Organisms Search } \\
\text { Optimization } \\
\text { Algorithm for } \\
\text { Scheduling of } \\
\text { Tasks on Cloud } \\
\text { Computing } \\
\text { Environment }\end{array}$ & $\begin{array}{l}\text { Minimizing } \\
\text { makespan, } \\
\text { optimizing job } \\
\text { scheduling, and } \\
\text { reducing the } \\
\text { degree of } \\
\text { imbalance between } \\
\text { virtual machines }\end{array}$ & SOSSA & sos & PloS one & PLOS & $\begin{array}{l}\text { In a cloud computing } \\
\text { world, the proposed } \\
\text { hybrid algorithm } \\
\text { (SOSSA) has been } \\
\text { shown to outperform the } \\
\text { current standard SOS } \\
\text { algorithm in terms of } \\
\text { task scheduling. }\end{array}$ \\
\hline 2 & $\begin{array}{l}\text { Esugwu and } \\
\text { Adewumi. } \\
\text { (2017) }\end{array}$ & $\begin{array}{l}\text { Soft sets based } \\
\text { symbiotic } \\
\text { organisms search } \\
\text { algorithm for } \\
\text { resource discovery } \\
\text { in cloud computing } \\
\text { environment }\end{array}$ & $\begin{array}{l}\text { Maximizes } \\
\text { resource utilization }\end{array}$ & sssos & $\begin{array}{l}\text { PSO, SOS, } \\
\text { PSOSA, }\end{array}$ & $\begin{array}{l}\text { Future } \\
\text { generation } \\
\text { computer } \\
\text { systems }\end{array}$ & Elsevier & $\begin{array}{l}\text { The hybrid SSSOS } \\
\text { algorithm for optimizing } \\
\text { VMs resource selection } \\
\text { in cloud in minimal } \\
\text { time, have displayed a } \\
\text { fared well in finding } \\
\text { high number of global } \\
\text { solutions. }\end{array}$ \\
\hline 3 & $\begin{array}{l}\text { Choe et al., } \\
\text { (2018) }\end{array}$ & $\begin{array}{l}\text { Improved hybrid } \\
\text { symbiotic organism } \\
\text { search task- } \\
\text { scheduling } \\
\text { algorithm for cloud } \\
\text { computing }\end{array}$ & $\begin{array}{l}\text { Minimizing } \\
\text { makespan }\end{array}$ & $\begin{array}{l}\text { SA-CLS- } \\
\text { SOS }\end{array}$ & $\begin{array}{l}\text { SOS, SA- } \\
\text { SOS, CLS- } \\
\text { SOS }\end{array}$ & $\begin{array}{l}\text { KSII } \\
\text { Transactions } \\
\text { on Internet } \\
\text { and } \\
\text { Information } \\
\text { Systems }\end{array}$ & KSII & $\begin{array}{l}\text { An acute makespan } \\
\text { reduction was achieved. }\end{array}$ \\
\hline 4 & $\begin{array}{l}\text { Baharudin et } \\
\text { al., (2019) }\end{array}$ & $\begin{array}{l}\text { A Quasi- } \\
\text { Oppositional- } \\
\text { Chaotic Symbiotic } \\
\text { Organisms Search } \\
\text { algorithm for } \\
\text { global optimization } \\
\text { problems }\end{array}$ & $\begin{array}{l}\text { Makespan } \\
\text { minimization }\end{array}$ & QOCSOS & sOS & $\begin{array}{l}\text { Applied } \\
\text { Soft } \\
\text { Computing } \\
\text { Journal }\end{array}$ & Elsevier & $\begin{array}{l}\text { The technique } \\
\text { QOCSOS, is more } \\
\text { viable in dealing with } \\
\text { global optimization } \\
\text { problem }\end{array}$ \\
\hline 5 & $\begin{array}{l}\text { Baharudin et } \\
\text { al. (2019) }\end{array}$ & $\begin{array}{l}\text { Multi-Objective } \\
\text { Task Scheduling } \\
\text { Problems in Cloud } \\
\text { Computing } \\
\text { Environment based } \\
\text { on Symbiotic } \\
\text { Organisms Search } \\
\text { Algorithm with } \\
\text { Chaotic } \\
\text { Optimization } \\
\text { Strategy. }\end{array}$ & $\begin{array}{l}\text { Minimizing } \\
\text { makespan and } \\
\text { reduction of task } \\
\text { processing cost }\end{array}$ & CMSOS & $\begin{array}{l}\text { MSOS, EMS- } \\
\text { C, } \\
\text { ECMSMOO } \\
\text { and BOGA }\end{array}$ & $\begin{array}{l}\text { Journal of } \\
\text { Network } \\
\text { and } \\
\text { Computer } \\
\text { Applications }\end{array}$ & Elsevier & $\begin{array}{l}\text { In terms of Pareto fronts } \\
\text { for makespan and cost, } \\
\text { the CMSOS algorithm } \\
\text { outperformed the } \\
\text { compared algorithms. }\end{array}$ \\
\hline
\end{tabular}

TABLE III. COMPARISON OF THE EXISTING MOdIFIED AND HyBRID SOS TECHNIQUES IN CLOUd TASK SCHEDULING PROBLEM

\begin{tabular}{|l|l|l|l|l|l|l|l|l|}
\hline S/N & $\begin{array}{l}\text { Modified /Hybrid } \\
\text { Techniques }\end{array}$ & Settings & Makespan & Cost & $\begin{array}{l}\text { VMs } \\
\text { Utilization }\end{array}$ & $\begin{array}{l}\text { Response } \\
\text { Time }\end{array}$ & $\begin{array}{l}\text { Convergence } \\
\text { speed }\end{array}$ & Performance \\
\hline 1 & {$[24]$} & Dynamic & Minimizes & Less & High & More & Low & Less \\
\hline 2 & {$[25]$} & Dynamic & Minimizes & Less & More & More & Low & Less \\
\hline 3 & {$[26]$} & Dynamic & Minimizes & Less & more & High & Low & Less \\
\hline 4 & {$[27]$} & Dynamic & Minimizes & Less & Less & More & Low & Less \\
\hline 5 & {$[28]$} & Dynamic & Minimizes & Less & More & High & Low & Less \\
\hline 6 & {$[29]$} & Dynamic & Minimizes & Less & Less & Less & Low & Less \\
\hline 7 & {$[30]$} & Dynamic & Minimizes & Less & High & more & Low & Less \\
\hline 8 & {$[31]$} & Dynamic & Minimizes & Less & High & Less & Low & More \\
\hline 9 & {$[32]$} & Dynamic & Minimizes & More & Less & Less & Low & Less \\
\hline 10 & {$[33]$} & Dynamic & Minimizes & More & Less & more & Average & More \\
\hline 11 & {$[34]$} & Dynamic & Minimizes & Less & Less & Less & Average & Less \\
\hline 12 & {$[35]$} & Dynamic & Minimizes & Less & Less & Less & Low & More \\
\hline
\end{tabular}


An improved task scheduling algorithm for cloud computing using hybrid symbiotic organisms search technique has been presented by [32]. The proposed technique combines the Simulated Annealing (SA) and Chaotic local search (CLS) with SOS optimization technique to improve the convergence rate as well as to avoid being trapped at the local optimal region. Simulation results show that the hybrid SOS outperforms SOS, SA-SOS, and CLS-SOS in terms of convergence speed and makespan.

A soft sets-based symbiotic organisms search algorithm for resource detection has been built in a cloud computing environment [33]. The proposed technique tackles the uncertainty problems of resource selections in cloud computing environment. Furthermore, the hybridized approach incorporates the capabilities of the underlying approaches to efficiently handle tasks that must be performed during cloud resource discovery. As compared to the PSO, SOS, and PSOSA algorithms, the algorithm performed well in terms of finding a large number of good global solutions while minimizing resource collection time, search accuracy, search depth distribution, and the ability to escape premature convergence.

For global optimization problems, a Quasi-OppositionalChaotic Symbiotic Organisms Search algorithm has been developed by [34]. For a higher standard of performance and faster convergence, the technique combines Quasi-OppositionBased Learning (QOBL) and Chaotic Local search methods with traditional SOS. QOBL is used for population initialization and generation hopping, while CLS is used to target the new best population. The results of the experiments show that QOCSOS achieve a better global optimum solution with remarkable convergence speed as compared to the original SOS.

In another study, [35] presents an efficient search algorithm for a multi-objective task scheduling problems based on symbiotic organisms search with a chaotic optimization strategy in a cloud computing environment. The proposed technique employed chaotic strategy to generate initial ecosize (population) as well as using its chaotic sequence to replace the random sequence based component of the SOS phases. This process ensures diversity among species for global convergence. Furthermore, the approach guarantees optimum cost-makespan trade-offs. Therefore, the CMSOS algorithm outperformed the other algorithms in terms of Pareto fronts for task execution time and cost.

The analysis of Table 3 shows that more work needs to be done on Symbiotic Organism Search (SOS) algorithms to improve its convergence speed so as to enhance its performance in cloud task scheduling issues. This can be achieved by modifying the mutual features parameter that exist between two distinct species and by taking into cognizance the contribution of each species in the relation measured by equity rather than equality in the ecosystem. By this improvement, it will enhance equitable allocation/mapping of task to heterogenous VMs as well as balance the search process between local search and global search. This modified technique named G_SOS is in its incubation stage awaiting further improvement and implementation.

\section{CONCLUSION AND FUTURE WORK}

Many metaheuristic algorithms have been proposed to solve optimization problems in recent decades. Thus, metaheuristic research around the world has resulted in optimization techniques that have proved to be superior to conventional gradient-based approaches. Symbiotic Organisms Search algorithm (SOS) is a recent SI-based metaheuristic algorithm that was inspired by nature[19]. The SOS algorithm mimics the collaborative behavior observed in nature among distinct species in ecosystem. Though, there have not been any review work on symbiotic organism search algorithm based on task scheduling problems. The modified and enhanced versions of SOS are faced with some challenges when solving some complex optimization problems that needs extra synergy to resolve. Therefore, these algorithms, modified or enhanced, can still be improved by looking inward to the features of the basic (SOS) algorithm.

\section{ACKNOWLEGMENT}

I would like to appreciate the Nigerian Tertiary Education Trust Fund (TETFund) in partnership with Kogi State Polytechnic Lokoja for their support of this work.

\section{REFERENCES}

[1] S. H. H. Madni, M. S. A. Latiff, Y. Coulibaly, and S. M. Abdulhamid, "Recent advancements in resource allocation techniques for cloud computing environment: a systematic review," Cluster Comput., vol. 20, no. 3, pp. 2489-2533, 2017, doi: 10.1007/s10586-016-0684-4.

[2] S. H. H. Madni, M. S. Abd Latiff, S. M. Abdulhamid, and J. Ali, "Hybrid gradient descent cuckoo search (HGDCS) algorithm for resource scheduling in IaaS cloud computing environment," Cluster Comput., vol. 22, no. 1, pp. 301-334, 2019, doi: 10.1007/s10586-0182856-x.

[3] L. Liu, T. Luo, and Y. Du, "A new task scheduling strategy based on improved ant colony algorithm in IaaS layer," CITS 2019 - Proceeding 2019 Int. Conf. Comput. Inf. Telecommun. Syst., no. 61370132, pp. 610, 2019, doi: 10.1109/CITS.2019.8862055.

[4] K. Dubey, M. Kumar, and S. C. Sharma, "Modified HEFT Algorithm for Task Scheduling in Cloud Environment," Procedia Comput. Sci., vol. 125, pp. 725-732, 2018, doi: 10.1016/j.procs.2017.12.093.

[5] G. Natesan and A. Chokkalingam, "Multi-Objective Task Scheduling Using Hybrid Whale Genetic Optimization Algorithm in Heterogeneous Computing Environment,” Wirel. Pers. Commun., vol. 110, no. 4, pp. 1887-1913, 2020, doi: 10.1007/s11277-019-06817-w.

[6] Z. Tong, H. Chen, X. Deng, K. Li, and K. Li, “A novel task scheduling scheme in a cloud computing environment using hybrid biogeographybased optimization,” Soft Comput., vol. 23, no. 21, pp. 11035-11054, 2019, doi: 10.1007/s00500-018-3657-0.

[7] A. Shabani, B. Asgarian, S. A. Gharebaghi, M. A. Salido, and A. Giret, "A New Optimization Algorithm Based on Search and Rescue Operations,” Math. Probl. Eng., vol. 2019, 2019, doi: 10.1155/2019/2482543.

[8] A. E. Ezugwu, "Enhanced symbiotic organisms search algorithm for unrelated parallel machines manufacturing scheduling with setup times," Knowledge-Based Syst., vol. 172, pp. 15-32, 2019, doi: 10.1016/j.knosys.2019.02.005.

[9] X. S. Yang, "Nature-inspired optimization algorithms: Challenges and open problems,” J. Comput. Sci., vol. 46, p. 101104, 2020, doi: 10.1016/j.jocs.2020.101104.

[10] D. Gabi, A. S. Ismail, A. Zainal, and Z. Zakaria, "Quality of service task scheduling algorithm for time-cost trade off scheduling problem in cloud computing environment,” Int. J. Intell. Syst. Technol. Appl., vol. 18, no. 5, pp. 448-469, 2019, doi: 10.1504/IJISTA.2019.101952.

[11] X.-S. Yang, Nature-Inspired Algorithms and Applied Optimization, vol. 744, no. January. 2018. 
[12] E. Cuervas, D. Zaldivar, and M. Perez, "Advances in Metaheuristics Algorithms_ Methods and Applications,” vol. 775, no. April, p. 229, 2018, doi: 10.1007/978-3-319-89309-9.

[13] T. Dokeroglu, E. Sevinc, T. Kucukyilmaz, and A. Cosar, "A survey on new generation metaheuristic algorithms," Comput. Ind. Eng., vol. 137, no. May, p. 106040, 2019, doi: 10.1016/j.cie.2019.106040.

[14] N. M. A. Samee, S. S. Ahmed, and R. A. A. A. A. Seoud, "Metaheuristic algorithms for independent task scheduling in symmetric and asymmetric cloud computing environment," J. Comput. Sci., vol. 15, no. 4, pp. 594-611, 2019, doi: 10.3844/jcssp.2019.594.611.

[15] M. Abdullahi, M. A. Ngadi, S. I. Dishing, S. M. Abdulhamid, and M. J. Usman, "A survey of symbiotic organisms search algorithms and applications,” Neural Comput. Appl., vol. 32, no. 2, pp. 547-566, 2020, doi: 10.1007/s00521-019-04170-4.

[16] H. Shayanfar and F. S. Gharehchopogh, "Farmland fertility: A new metaheuristic algorithm for solving continuous optimization problems," Appl. Soft Comput. J., vol. 71, pp. 728-746, 2018, doi: 10.1016/j.asoc.2018.07.033.

[17] D. Gabi, A. S. Ismail, A. Zainal, Z. Zakaria, and A. Abraham, "Orthogonal Taguchi-based cat algorithm for solving task scheduling problem in cloud computing,” Neural Comput. Appl., vol. 30, no. 6, pp. 1845-1863, 2018, doi: 10.1007/s00521-016-2816-4.

[18] A. A. Zubair, S. B. A. Razak, M. A. B. Ngadi, A. Ahmed, and S. H. H. Madni, Convergence-based task scheduling techniques in cloud computing: A review, vol. 1073. 2020.

[19] M. Y. Cheng and D. Prayogo, "Symbiotic Organisms Search: A new metaheuristic optimization algorithm," Comput. Struct., vol. 139, pp. 98-112, 2014, doi: 10.1016/j.compstruc.2014.03.007.

[20] G. Xiong, J. Zhang, X. Yuan, D. Shi, and Y. He, "Application of symbiotic organisms search algorithm for parameter extraction of solar cell models,” Appl. Sci., vol. 8, no. 11, 2018, doi: 10.3390/app8112155.

[21] A. E. Ezugwu and D. Prayogo, "Symbiotic Organisms Search Algorithm: theory, recent advances and applications," Expert Syst. Appl., vol. 119, pp. 184-209, 2019, doi: 10.1016/j.eswa.2018.10.045.

[22] Y. Zhou, H. Wu, Q. Luo, and M. Abdel-Baset, "Automatic data clustering using nature-inspired symbiotic organism search algorithm," Knowledge-Based Syst., vol. 163, pp. 546-557, 2019, doi: 10.1016/j.knosys.2018.09.013.

[23] G. G. Tejani, N. Pholdee, S. Bureerat, and D. Prayogo, "Multiobjective adaptive symbiotic organisms search for truss optimization problems," Knowledge-Based Syst., vol. 161, pp. 398-414, 2018, doi: 10.1016/j.knosys.2018.08.005.

[24] M. Abdullahi, M. A. Ngadi, and S. M. Abdulhamid, "Symbiotic Organism Search optimization based task scheduling in cloud computing environment,” Futur. Gener. Comput. Syst., vol. 56, pp. 640-650, 2016, doi: 10.1016/j.future.2015.08.006.
[25] M. Abdullahi, M. Asri Ngadi, and S. I. Dishing, "Chaotic symbiotic organisms search for task scheduling optimization on cloud computing environment," 6th ICT Int. Student Proj. Conf. Elev. Community Through ICT, ICT-ISPC 2017, vol. 2017-Janua, pp. 1-4, 2017, doi: 10.1109/ICT-ISPC.2017.8075340.

[26] L. R. Rodrigues, J. P. P. Gomes, A. R. R. Neto, and A. H. Souza, “A Modified Symbiotic Organisms Search Algorithm Applied to Flow Shop Scheduling Problems,” 2018 IEEE Congr. Evol. Comput. CEC 2018 Proc., p. 8477846, 2018, doi: 10.1109/CEC.2018.8477846.

[27] D. Srivastava and M. Kalra, "Improved symbiotic organism search based approach for scheduling jobs in cloud,” Lect. Notes Networks Syst., vol. 116, no. Iciil, pp. 453-461, 2020, doi: 10.1007/978-981-153020-3_39.

[28] Z. Liu, X. Liu, Y. Dong, X. Zhao, and B. Zhang, "CTS-SOS: Cloud task scheduling based on the symbiotic organisms search," Commun. Comput. Inf. Sci., vol. 729, pp. 82-94, 2017, doi: 10.1007/978-981-106442-5_8.

[29] A. E. Ezugwu, O. J. Adeleke, and S. Viriri, "Symbiotic organisms search algorithm for the unrelated parallel machines scheduling with sequence-dependent setup times," PLoS One, vol. 13, no. 7, pp. 1-23, 2018, doi: 10.1371/journal.pone.0200030.

[30] M. Yuan, C. Richard, and A. Gosno, "SOS 2 . 0: an evolutionary approach for SOS algorithm,” Evol. Intell., no. 0123456789, 2020, doi: 10.1007/s12065-020-00476-8.

[31] M. Abdullahi and M. A. Ngadi, "Hybrid symbiotic organisms search optimization algorithm for scheduling of tasks on cloud computing environment,” PLoS One, vol. 11, no. 6, pp. 1-29, 2016, doi: 10.1371/journal.pone.0158229.

[32] S. Choe, B. Li, I. Ri, C. Paek, J. Rim, and S. Yun, "Improved hybrid symbiotic organism search task-scheduling algorithm for cloud computing,” KSII Trans. Internet Inf. Syst., vol. 12, no. 8, pp. 35163541, 2018, doi: 10.3837/tiis.2018.08.001.

[33] A. E. Ezugwu and A. O. Adewumi, "Soft sets based symbiotic organisms search algorithm for resource discovery in cloud computing environment,” Futur. Gener. Comput. Syst., vol. 76, pp. 33-50, 2017, doi: 10.1016/j.future.2017.05.024.

[34] K. H. Truong, P. Nallagownden, Z. Baharudin, and D. N. Vo, “A QuasiOppositional-Chaotic Symbiotic Organisms Search algorithm for global optimization problems,” Appl. Soft Comput. J., vol. 77, pp. 567-583, 2019, doi: 10.1016/j.asoc.2019.01.043.

[35] M. Abdullahi, M. A. Ngadi, S. I. Dishing, S. M. Abdulhamid, and B. I. eel Ahmad, "An efficient symbiotic organisms search algorithm with chaotic optimization strategy for multi-objective task scheduling problems in cloud computing environment," J. Netw. Comput. Appl., vol. 133, no. July 2018, pp. 60-74, 2019, doi: 10.1016/j.jnca.2019.02.005. 